\title{
Extreme Hypernatraemia and Sepsis in a Patient with Huntington's Dementia: A Conundrum in Fluid Management
}

\author{
Harish Venkatesh ${ }^{1 \#}$, Sanjeev Ramachandran ${ }^{2 * \#}$, Atanu Basu $^{3}$ and Hari Nair \\ ${ }^{1}$ Royal Berkshire NHS Foundation Trust, United Kingdom \\ ${ }^{2}$ University Hospitals of Leicester, United Kingdom \\ ${ }^{3}$ Glan Clwyd Hospital, United Kingdom \\ \#Joint first authors.
}

*Corresponding author: Dr. Sanjeev Ramachandran, MBBS, BSC, University Hospitals of Leicester, Leicester Royal Infirmary, Infirmary Square, Leicester LE1 5WW, United Kingdom

\begin{abstract}
Summary
We report a unique case of extreme hypernatraemia of 196 $\mathrm{mmol} / \mathrm{L}$ and severe sepsis in a young 39-year-old adult with Huntington's dementia, which presented a challenge in fluid management. The hypernatraemia was thought to be caused by chronic severe dehydration from poor intake and the sepsis was thought to have started as an inadequately treated urinary tract infection. The patient was initially treated aggressively with hypotonic saline and intravenous antibiotics but was subsequently managed using a slower correction rate after identifying the chronic nature of the natraemia. To our knowledge, this is the first reported case of extreme hypernatraemia and severe sepsis manifesting concomitantly in such a young patient. We highlight the difficulties of balancing the risks and benefits of rapid versus slow fluid resuscitation in such complex clinical situations. We advocate early identification of chronic hypernatraemia, accurate calculation of free water deficit and effective administration of intravenous fluids that is decided on a case-by-case basis.
\end{abstract}

\section{Background}

Hypernatraemia is a common electrolyte disturbance defined as a rise in serum sodium level exceeding 145 $\mathrm{mmol} / \mathrm{L}$, or more specifically as a loss of total body water relative to electrolyte content. It is a clinical condition which presents in various ways depending on the severity, ranging from headaches to seizures and coma [1]. It is more common in the elderly population and children [1], with adult mortality rates ranging from 20 to $60 \%$ [2-5]. According to one study, approximately 1 to $2 \%$ of patients attending the Emergency Department have hypernatraemia, often with a variety of aetiologies [6]. Hypernatraemia over $160 \mathrm{mmol} / \mathrm{L}$ is considered to be very severe [7] and as such needs to be treated with special caution. We report a unique case of extreme hypernatraemia and severe sepsis in a young adult with Huntington's dementia, which presented a conundrum in fluid management in our Emergency Department.

\section{Case Presentation}

In November 2014, a 39-year-old man with Huntington's disease presented to the Emergency Department with reduced consciousness and signs of dehydration. He lived in a nursing home receiving one-to-one care and was unable to communicate verbally due to Huntington's dementia. 3 days before his admission, he had been started on trimethoprim for a confirmed urinary tract infection by his General Practitioner. On admission he was tachycardic at 104 beats per minute, tachypneic at 26 breaths per minute and had an $\mathrm{SpO}_{2}$ of $83 \%$. Examination showed diaphoresis, signs of severe dehydration and basal crepitations on auscultation. Initial blood tests showed a sodium level of $196 \mathrm{mmol} / \mathrm{L}$, leukocytosis (total white cell count of $26.3 \times 10^{9} / \mathrm{L}$, neutrophil count of $23.8 \times 10^{9} / \mathrm{L}$ ) and renal impairment (blood urea of $34.1 \mathrm{mmol} / \mathrm{L}$ and serum creatinine of $217 \mathrm{mmol} / \mathrm{L}$ ). Chest radiograph revealed no active pulmonary patho-

Citation: Venkatesh H, Ramachandran S, Basu A, Nair H (2019) Extreme Hypernatraemia and Sepsis in a Patient with Huntington's Dementia: A Conundrum in Fluid Management. Int J Crit Care Emerg Med 5:064. doi.org/10.23937/2474-3674/1510064

Accepted: January 03, 2019: Published: January 05, 2019

Copyright: (C) 2019 Venkatesh $\mathrm{H}$, et al. This is an open-access article distributed under the terms of the Creative Commons Attribution License, which permits unrestricted use, distribution, and reproduction in any medium, provided the original author and source are credited. 
logy. A low urine output excluded diabetes insipidus. A diagnosis of extreme hypernatraemia and acute kidney injury secondary to presumed urosepsis was made and initial treatment in the Emergency Department included aggressive fluid therapy $(1000 \mathrm{ml}$ of $0.45 \%$ saline over 3 hours), Intravenous (IV) antibiotics and hydrocortisone.

However, after carefully reviewing the patient and his background history, we further deduced that his hypernatraemia was caused by chronic dehydration. After calculating his free water deficit, his IV fluid regime was slowed down with the aim of reducing his sodium levels by no more than $8 \mathrm{mmol} / \mathrm{L}$ per day. He was then transferred to the Acute Medical Unit under the care of the renal physicians.

\section{Outcome and Follow-up}

On Day 2 of his admission the patient's sodium levels had come down to $186 \mathrm{mmol} / \mathrm{L}$, however he became more unresponsive and was generally deteriorating. His blood culture returned positive for Staphylococcus aureus, which was sensitive to the antibiotics he was already prescribed. After speaking to his family, it was agreed that he was forward-based care and not for resuscitation. It was decided that he be put on the End of Life Care Pathway, through which palliative care was initiated. By Day 3, sodium levels had lowered to 180 $\mathrm{mmol} / \mathrm{L}$, but the patient further deteriorated due to possible aspiration; his arterial blood gas was in keeping with a picture of severe hypoxia. He passed away on Day 4, after treatment was withdrawn the night before in order to keep him comfortable.

\section{Discussion}

We report the case of a patient with Huntington's dementia presenting with extreme hypernatraemia, complicated by severe sepsis. To the best of our knowledge, this is the first reported case of both clinical issues manifesting concomitantly, raising a challenge in fluid management. Extreme hypernatraemia is treated by calculating the free water deficit [8] and administering slow IV fluids generally aimed at lowering the sodium level cautiously in order to prevent cerebral oedema [9].

However, given the rarity of cases of extreme hypernatraemia, the evidence base supporting interventions in such situations is lacking. Few reports have discussed cases of extreme hypernatraemia in adults, which were managed using slow hypotonic saline [10] and haemodialysis [9]. Both methods were effective in treating extreme hypernatraemia, with no neurological sequelae. One study showed that there is a poorer prognosis for patients presenting to hospital with hypernatraemia and suggested that less aggressive fluid therapy may be beneficial for such patients [11]. In contrast, an important study retrospectively evaluating treatment and outcomes for 85 patients admitted to the Emergency Department with severe hypernatraemia (>
$150 \mathrm{mmol} / \mathrm{L}$ ) revealed that correcting hypernatraemia too slowly was also associated with increased mortality, regardless of initial natraemia [12]. One issue identified by this study pertaining to ineffective management of severe hypernatraemia was that only $3.5 \%$ of the patient cohort was weighed - an essential component for calculating free water deficit. Furthermore, the study highlighted that patients who were institutionalised and suffered from dementia were particularly at risk of developing severe hypernatraemia, reflecting the characteristics of our patient. Although consensus has not been reached regarding optimal correction, experts agree that correction speed should not exceed $1 \mathrm{mmol} / \mathrm{L} /$ hour, whilst simultaneously aiming to shorten period of hypernatraemia [1,13-15]. In our case, however, the aforementioned considerations need to be weighed up against the need for more aggressive fluid therapy to maintain end organ perfusion in the context of sepsis.

In summary, we highlight the difficulty of balancing the risks and benefits of rapid fluid resuscitation, necessitated by severe sepsis and acute kidney injury, against the complexities of fluid resuscitation in correcting such an extreme hypernatraemia.

\section{Learning Points}

- Fluid therapy regimes in complex clinical scenarios should be decided on a case-by-case basis, taking into account all clinical factors and the underlying physiology of the patient.

- The presence and aetiology of chronic hypernatraemia should be identified as early on in the course of the patient's care as possible. This is especially important in high risk patients such as those institutionalised and suffering from dementia.

- In cases of severe and extreme hypernatraemia in particular, accurate calculation of free water deficit is essential to manage the patient effectively. In line with this, we must ensure that such patients are always weighed on admission.

\section{References}

1. Adrogue HJ, Madias NE (2000) Hypernatremia. N Engl J Med 342: 1493-1499.

2. Arampatzis $S$, Frauchiger B, Fiedler GM, Leichtle AB, Buhl D, et al. (2012) Characteristics, symptoms, and outcome of severe dysnatremias present on hospital admission. Am J Med 125: 1125.e1-1125.e7.

3. Barsoum NR, Levine BS (2002) Current prescriptions for the correction of hyponatraemia and hypernatraemia: Are they too simple? Nephrol Dial Transplant 17: 1176-1180.

4. Palevsky PM, Bhagrath R, Greenberg A (1996) Hypernatremia in hospitalized patients. Ann Intern Med 124: 197-203.

5. Funk GC, Lindner G, Druml W, Metnitz B, Schwarz C, et al. (2010) Incidence and prognosis of dysnatremias present on ICU admission. Intensive Care Med 36: 304-311. 
6. Arampatzis $S$, Exadaktylos A, Buhl D, Zimmermann $H$, Lindner $G$ (2012) Dysnatraemias in the emergency room: Undetected, untreated, unknown? Wien Klin Wochenschr 124: 181-183.

7. Aiyagari V, Deibert E, Diringer MN (2006) Hypernatremia in the neurologic intensive care unit: How high is too high? J Crit Care 21: 163-172.

8. Braun MM, Barstow CH, Pyzocha NJ (2015) Diagnosis and management of sodium disorders: Hyponatremia and hypernatremia. Am Fam Physician 91: 299-307.

9. Yang YF, Wu VC, Huang CC (2005) Successful management of extreme hypernatraemia by haemofiltration in a patient with severe metabolic acidosis and renal failure. Nephrol Dial Transplant 20: 2013-2014.

10. Jeffery J, Ayling RM, McGonigle RJ (2007) Successful rescue of severe hypernatraemia $(196 \mathrm{mmol} / \mathrm{L})$ by treatment with hypotonic fluid. Ann Clin Biochem 44: 491-494.
11. Maggs FG (2014) The management of patients presenting with hypernatraemia: Is aggressive management appropriate? Clin Med 14: 260-263.

12. Bataille S, Baralla C, Torro D, Christophe B (2014) Undercorrection of hypernatremia is frequent and associated with mortality. BMC Nephrol 15.

13. Fall PJ (2000) Hyponatremia and hypernatremia. A systematic approach to causes and their correction. Postgrad Med 107: 75-82.

14. Oufella HA, Offenstadt G (2003) Disorders of water, electrolytes and acid-base equilibrium. Rev Prat 53: 883-891.

15. Tareen N, Martins D, Nagami G, Levine B, Norris KC (2005) Sodium disorders in the elderly. J Natl Med Assoc 97: 217-224. 